\title{
Nidia Catherine González \\ ¿Participación ciudadana y cultura política en Colombia? Un contraste de las experiencias de la Asamblea Constituyente de Mogotes y del Proyecto Nasa del Cauca
}

\section{Introducción}

Entre los países de la región andina, Colombia se distingue como el epicentro de una contradicción: es la nación, a nivel formal con una de las democracias más estables y antiguas de América Latina, pero al mismo tiempo, su territorio es lugar de un conflicto armado interno que dura ya más de medio siglo y de una cultura ilegal del narcotráfico. Aun así, en su historia reciente se han desarrollado experiencias locales de grupos comunitarios cuyas acciones políticas verifican un avance hacia la materialización de la democracia participativa, así como la gestación de una cultura política a favor de la solución negociada del conflicto y la construcción de la paz.

Teniendo en cuenta que la aproximación a la realidad colombiana que voy a explorar en este artículo gira alrededor de dos temas, la participación ciudadana en Colombia y su cultura política, ambos abordados desde una perspectiva empírica con base en las dos experiencias nombradas, a continuación haré una breve contextualización de dichas experiencias. El proceso constituyente de Mogotes se enmarca en el conjunto de Asambleas Constituyentes ${ }^{1}$ del país, que son un efecto novedoso de los mecanismos constitucionales de participación política y que en total suman aproximadamente 135 en todo el territorio nacional; algunas son de cobertura local, otras municipal y otras departamental (CINEP 2007: 5-18). Esta Constituyente gana el "Premio Nacional de Paz" en 1999, reflejando el esfuerzo de una po-

1 El poder constituyente es el emanado de la sociedad civil, gracias a los mecanismos de participación establecidos con la Constitución de 1991, los cuales buscan garantizar este ejercicio político popular. 
blación mayoritariamente mestiza y urbana por encontrar caminos hacia la participación y la construcción de una cultura política.

Por otra parte, el Proyecto Nasa surge dentro de un proceso de movilización indígena nasa, cuyo origen se remonta a la conquista y la colonia; aunque éste se institucionaliza como proyecto comunitario local sólo en 1980 (González 2006b: 102-122). Hacia finales de los noventa y principios del 2000 ésta experiencia indígena se ha distinguido por ser una alternativa real, autónoma y orgánica frente a la confrontación armada colombiana (González 2006b: 122-164). Es conveniente aclarar que en Colombia la población indígena representa sólo un 2\% del total de habitantes; sin embargo, la etnia nasa es el segundo grupo indígena más numeroso $\mathrm{y}$, políticamente ha tenido el mayor impacto a nivel nacional (UAEDT/DNP 1998: 2001). ${ }^{2}$

Tanto el movimiento indígena nasa del norte del Cauca colombiano, como el proceso de la Asamblea Constituyente de Mogotes han sido reconocidos como modelos del ejercicio democrático participativo promulgado en la Constitución de 1991. El primero desde una propuesta indígena rural en oposición a la violencia estructural y la ineficacia política y económica del sistema nacional y, la segunda, como una experiencia de organización ciudadana urbana para reclamar sus derechos y su soberanía local, cuya envergadura política fue significativa, pero menor a la que ha tenido la propuesta indígena.

El propósito de esta contribución es verificar la potencialidad del Proyecto Nasa y del proceso Constituyente de Mogotes de ejercer un modelo de democracia alternativo; así, también, se pretende constatar la vigencia de una cultura y participación política desde las particularidades de ambos procesos.

Esta propuesta de análisis comparado contrasta la potencialidad del Proyecto Nasa y de la Asamblea Constituyente de Mogotes para ejercer en el panorama continental, un modelo de democracia alternativo; de igual forma, constata la vigencia de una cultura y participa-

2 La etnia nasa, también conocidos como paeces, habita principalmente el departamento del Cauca, y en menor proporción en los departamentos de Caquetá, Huila, Putumayo, Tolima y Valle del Cauca en Colombia. En el Cauca los nasa se han instalado mayoritariamente en la zona norte, constituida por $191.318 \mathrm{hec}-$ táreas, siete municipios y los siguientes resguardos: Concepción, Guadualito, Delicias, Munchique, Canoas, Tóez, Huellas, Caloto, Corinto, San Francisco, Tacueyó, Toribío y Jambaló (cabildos indígenas de Tacueyó, San Francisco y Toribío, 2000). 
ción política desde las particularidades de ambos procesos. Para abarcar esta cuestión analizaremos inicialmente algunos lastres generales de la sociedad colombiana, que nos ayudaran a comprender cuáles pueden ser algunos de los retos para mejorar nuestro sistema político, cultural y social, así como también nos permiten dimensionar el gran significado de los esfuerzos locales por proponer espacios alternativos de construcción política.

En segunda medida, este trabajo se dedicará a caracterizar las dos experiencias objeto de estudio, con base en los siguientes interrogantes: ¿demuestran los procesos del Proyecto Nasa y de la Asamblea Constituyente de Mogotes, acciones políticas de consolidación de una democracia participativa alternativa en Colombia?; ¿cuáles son sus principales fortalezas y tensiones en términos de la construcción de cultura y participación política?

\section{Nudos estructurales de la cultura política}

Quiero comenzar éste análisis presentando dos contradicciones relacionadas con la participación ciudadana y la cultura política colombiana, las cuales son recogidas en las siguientes preguntas: ¿cómo existe en Colombia un sistema político formalmente estructurado y constitucionalmente democrático participativo, ${ }^{3}$ pero en sus prácticas ciudadanas demasiado incipiente?, y ¿por qué la cultura política más que ser un ejercicio consciente y ciudadano que facilite el conocimiento, el compromiso y la valoración del sistema político, se manifiesta como un reflejo de ciertos nudos que limitan la maduración de nuestra cultura política?

Estas y otras preguntas de la particular realidad colombiana son las que animaron una indagación más profunda sobre aquellos nudos que no han permitido en Colombia la materialización de una partici-

3 CONSTITUCION POLITICA DE COLOMBIA 1991, PREAMBULO, EL PUEBLO DE COLOMBIA en ejercicio de su poder soberano, representado por sus delegatarios a la Asamblea Nacional Constituyente, invocando la protección de Dios, y con el fin de fortalecer la unidad de la Nación y asegurar a sus integrantes la vida, la convivencia, el trabajo, la justicia, la igualdad, el conocimiento, la libertad y la paz, dentro de un marco jurídico, democrático y participativo que garantice un orden político, económico y social justo, y comprometido a impulsar la integración de la comunidad latinoamericana decreta, sanciona y promulga la siguiente... (LEGIS 2007: 18). 
pación ciudadana y de una cultura política. En lo siguiente desarrollo mi cavilación acerca de los que considero son los nudos estructurales que limitan la consolidación de una democracia participativa en éste país.

Un primer nudo reflejo en la cultura política colombiana, así como en algunos países de América Latina, principalmente de su zona andina, está representado en la siguiente dualidad: una cultura dominante excluyente y unas prácticas clientelistas de inclusión. Esta dualidad mimetiza la exclusión cultural a través de formas de inclusión formal. La Constitución colombiana de 1991 es una de las más modernas continentalmente (Barié 2000: 75-84); sin embargo, en la práctica se reduce a la arena electoral. La maquinaria consolidada promueve un discurso de participación democrática ciudadana durante las elecciones, pero en los períodos administrativos de los elegidos se dedica a reproducir vicios de la política tradicional, como el clientelismo y la corrupción, conjugados éstos con ciertos esquemas culturales de exclusión característicos de las sociedades latinoamericanas.

Estos esquemas de exclusión son suscitados por una serie de antivalores como los prejuicios, los estereotipos, la discriminación, la negación de lo popular y la desigualdad (Wills Obregón 2002: 44-57). Por décadas y décadas la historia oficial y los parámetros sociales convencionales nos han obligado a reconocer al blanco o al mestizo como más culto y civilizado que el negro o el indígena, al propietario como más influyente y merecedor que el pobre o marginado, al joven como más productivo que el adulto mayor o el niño (Wills Obregón 2002: 49). Así las cosas, nuestras sociedades latinoamericanas manejan amplios márgenes de exclusión, no sólo desde la desigualdad socio-económica sino desde los prejuicios, las jerarquías, los estigmas morales y sociales, donde están arraigadas las creencias y representaciones colectivas (Elias 1996: 229-242).

Respecto al tema étnico e indígena, esta discriminación social, política y cultural se relaciona con una negación del otro, con un no reconocimiento de lo diferente, cuestión que nos llevaría a pesar más en la necesidad de crear puentes hacia la interculturalidad. Sin embargo, comprendiendo que estos temas no son el objeto principal de este artículo, no voy a profundizar en los mismos. Lo que es imprescindible en esta reflexión conjunta es reconocer que estos nudos estructurales y sus consecuencias tienen colindancia con la consolidación o no de 
una cultura política verdaderamente democrática, participativa e incluyente.

Un segundo nudo estructural de la historia colombiana es la violencia sistemática que lamentablemente caracteriza nuestro país. Si bien se ha estudiado en gran parte la violencia producto del conflicto armado, no se han investigado suficientemente los orígenes y las prácticas de la violencia social. En Colombia, de las veinte personas que son asesinadas diariamente, cinco son víctimas directas del conflicto armado y quince, blanco de actos de criminalidad social (PNUD 2003: 112-124). A ese respecto existen cifras significativas en términos de violencia intrafamiliar, abuso a menores, robos a mano armada, etc.; estos actos delictivos, desde mi valoración, tienen amplias raíces en un aprendizaje cultural que facilita la "sobrevivencia por medio de acciones violentas" y que tiene relación con las acciones ciudadanas. Es fundamental comprender esta correlación si se pretende lograr que los ciudadanos nos convirtamos en sujetos de mejoramiento intrasocial.

Un tercer nudo está representado por la ilegalidad, que marca otra especificidad del caso colombiano. La ilegalidad no sólo vincula los actos delictivos del narcotráfico sino también los del contrabando de bienes de consumo y de armas, así como con el lavado de activos. Lamentablemente éste es otro rasgo que marca a la sociedad colombiana y que ha permeado todos los estratos sociales, tanto a las clases populares y las periferias urbanas y rurales, como a la dirigencia política y a las élites social y económica (Camacho Guizado 1991: 65-73). Dentro de mi observación y estudio, esa posibilidad productiva ilegal ampliamente rentable ha permitido que aquellos ciudadanos coaccionados - por la desigualdad socio-económica, por los prejuicios socioculturales y por el accionar de los grupos armados- aseguren su sobrevivencia por medio de diversas formas de economía subterránea (Arango et al. 2004).

Esta cadena perversa de relaciones sociales y productivas ha formado ciudadanos ausentes de voluntad, el ciudadano común solamente tiene la opción de ocuparse de asegurar su sobrevivencia y la de su familia, así como de solucionar la exclusión que de diferentes maneras lo presiona. En este marco se hace comprensible que a nivel político estos votantes sean presas fáciles de la maquinaria electoral, de la 
persuasión de los caciques politiqueros por motivos económicos o de seguridad. $^{4}$

Colombia ha sido reconocida formalmente como una de las democracias más estables de Latinoamérica; sin embargo, dicha estabilidad sólo es verificable en lo electoral, ya que en la mayoría del territorio colombiano el ejercicio electoral no representa una acción consciente que incluya el conocimiento, compromiso y valoración de la opción política, sino más bien una práctica obligada por el cacique político de turno, el patrón (armado o potentado) que ofrece una contraprestación puntual. ${ }^{5}$ De esta manera, temas como el carácter, el espacio, las políticas y los servicios públicos, así como el cumplimiento de la ley son algo ajeno y en muchos casos desconocido para el común de los colombianos (AFP 2007).

Estos nudos estructurales de la cultura y la historia nacionales proponen inaplazables debates a la hora de pensar en la materialización de la cultura y la participación políticas. Son de importancia, asimismo, cuando se trata de construir una integración andina: es fundamental comparar si tienen lugar o afectan también las sociedades de Ecuador, Venezuela, Perú y Bolivia.

\section{Iniciativas locales hacia la democracia}

Luego de este panorama, el cual se aproxima de manera crítica a los nudos estructurales que históricamente han socavado la materialización de la democracia en Colombia, pretendo en lo siguiente presentarles una perspectiva más proactiva, identificando dos iniciativas locales cuyas acciones han fomentado directa o indirectamente el de-

4 Sin datos precisos de las zonas, el ministro comentó que de los 1.099 municipios que existen en Colombia, el 7\% (77), está en alto riesgo electoral, es decir, que las elecciones pueden ser afectadas por varias situaciones, ya sea intimidación de grupos armados ilegales contra electores y candidatos, por financiación ilícita de campañas, compra y venta de votos, y otros mecanismos de fraude electoral (Molina Ramírez 2007).

5 En un informe, la Organización de Estados Americanos (OEA) dijo que "Un número considerable de los observadores de la Misión constató personalmente cómo de manera casi pública se entregaba dinero en efectivo o bolsas con alimentos para obtener el voto favorable para uno u otro candidato". Precisó que en un $8 \%$ de los puestos de votación observados - sin indicar el total- se presenció compra de votos", mientras que "en el $4 \%$ hubo evidencia de amenazas y/o violencia dirigida a electores" (AFP 2007). 
sarrollo de la cultura política y la participación ciudadana en el territorio nacional. En Colombia, durante las últimas tres décadas, ha tenido lugar un florecimiento de iniciativas de tipo nacional, regional y local en pro de la construcción de la paz, la democracia, la movilización política y la participación política; asimismo, varios académicos se han interesado en profundizar mucho más sobre estas temáticas (CINEP 2007: 25-43; García-Durán 2004: 18-70; Hernández 2005; Hernández 2002; 2003; González 2008; INDEPAZ 2000; Rettberg Beil 2006). Dentro de este amplio horizonte de formas organizativas, he propuesto la siguiente tipología que caracteriza la cobertura, el principal quehacer de las mismas.

La siguiente tabla recoge brevemente los diferentes esfuerzos en pro de la construcción colectiva de paz y de participación ciudadana; estas tendencias reflejan que, paralelamente al escalamiento del conflicto, existe un esfuerzo de muchas comunidades de colombianos que afectados por el mismo, han hecho grandes esfuerzos por transformar la realidad de nuestro país. Este artículo se concentra en los dos casos ya mencionados, pues son dos iniciativas comunitarias locales que han logrado efectos significativos en términos de construcción de ciudadanía, de análisis y solución de las consecuencias del conflicto y de un ejercicio alternativo de la democracia participativa. A continuación se presenta una caracterización de las fortalezas de cada una de ellas, y posteriormente se anotan algunas de sus tensiones internas. 
Tipología de iniciativas por la paz en Colombia, según su cobertura

\begin{tabular}{|c|c|c|c|}
\hline $\begin{array}{l}\text { Cober- } \\
\text { tura }\end{array}$ & Local & Regional & Nacional \\
\hline $\begin{array}{l}\text { Inicia- } \\
\text { tivas }\end{array}$ & $\begin{array}{l}\text { Iniciativas de base } \\
\text { anti-hegemónicas: } \\
\text { se distinguen por } \\
\text { proponer esquemas } \\
\text { alternativos frente a } \\
\text { problemas estructu- } \\
\text { rales, así apuestan a } \\
\text { la solución negocia- } \\
\text { da del conflicto, a la } \\
\text { soberanía alimenta- } \\
\text { ria, a la autonomía } \\
\text { como pueblos y a la } \\
\text { vida social comuni- } \\
\text { taria. Ej.: Proyecto } \\
\text { Nasa. }\end{array}$ & $\begin{array}{l}\text { Iniciativas de desa- } \\
\text { rrollo y paz: pro- } \\
\text { mueven el desarro- } \\
\text { llo de la paz a través } \\
\text { de proyectos pro- } \\
\text { ductivos e interlo- } \\
\text { cución con los acto- } \\
\text { res directos e indi- } \\
\text { rectos vinculados al } \\
\text { conflicto en su ex- } \\
\text { presión regional. } \\
\text { Ej.: Programa por la } \\
\text { Paz del Magdalena } \\
\text { Medio (PPMMD). }\end{array}$ & $\begin{array}{l}\text { Iniciativas de educación para } \\
\text { la paz y resolución de con- } \\
\text { flictos: representa todas estas } \\
\text { metodologías y/o organiza- } \\
\text { ciones dedicadas a transfor- } \\
\text { mar los distintos tipos de } \\
\text { conflicto emergentes en } \\
\text { nuestra sociedad. Ej.: Institu- } \\
\text { to de Estudios para el Desa- } \\
\text { rrollo y la Paz (Indepaz). }\end{array}$ \\
\hline & $\begin{array}{l}\text { Iniciativas de base } \\
\text { en resistencia a la } \\
\text { violencia y el con- } \\
\text { flicto: suceden en } \\
\text { zonas de alta con- } \\
\text { flictividad armada } \\
\text { como respuesta de } \\
\text { la sociedad en pro } \\
\text { de la defensa de su } \\
\text { neutralidad política. } \\
\text { y de la protección a } \\
\text { sus derechos funda- } \\
\text { mentales. Ej.: Cam- } \\
\text { pesinos del Carare, } \\
\text { Comunidades de } \\
\text { Paz del Cacarica. } \\
\end{array}$ & & $\begin{array}{l}\text { Iniciativas estatales de diálo- } \\
\text { go y negociación. Ej.: todas } \\
\text { las políticas gubernamentales } \\
\text { relación a los actores arma- } \\
\text { dos ilegales. }\end{array}$ \\
\hline
\end{tabular}




\begin{tabular}{|l|l|l|}
\hline $\begin{array}{l}\text { Iniciativas de base a favor de la democra- } \\
\text { cia y el desarrollo local. Se establecen para } \\
\text { promover la participación ciudadana en } \\
\text { procesos democráticos relacionados con } \\
\text { temas públicos y/o de interés general. Ej.: } \\
135 \text { Asambleas Constituyentes entre éstas } \\
\text { la Asamblea Constituyente de Mogotes. }\end{array}$ & $\begin{array}{l}\text { Iniciativas recientes de movi- } \\
\text { lización masiva por la paz: } \\
\text { movilizaciones nacionales de } \\
\text { los últimos años, que expre- } \\
\text { san la polarización de la so- } \\
\text { ciedad en general y de los } \\
\text { medios masivos de comuni- } \\
\text { cación. Esta polarización } \\
\text { oscila entre quienes están a } \\
\text { favor de una mirada del con- } \\
\text { flicto en pro del estableci- } \\
\text { miento y en su contra. Ej: } \\
\text { Marcha del 4 de febrero } \\
\text { contra el secuestro. }\end{array}$ \\
\hline & $\begin{array}{l}\text { Iniciativas de coordinación regional y nacional: re- } \\
\text { presentan el trabajo de ONG’s que a nivel nacional } \\
\text { coordinan el desarrollo de ciertas agendas orienta- } \\
\text { das a consolidar procesos de construcción de paz. } \\
\text { Ej.: Red de Iniciativas por la paz y contra la guerra } \\
\text { Redepaz). }\end{array}$ \\
\hline
\end{tabular}

\section{El Proyecto Nasa}

El Proyecto Nasa es una expresión comunitaria local del movimiento indígena Nasa del Cauca colombiano. Este movimiento cubre el departamento homónimo y está organizado formalmente en una estructura departamental, el Consejo Regional Indígena del Cauca (CRIC), que está constituido por ocho organizaciones zonales y proyectos de cobertura local. El Proyecto Nasa se ubica en la zona norte, donde trabaja la Asociación de Cabildos Indígenas del Norte del Cauca (ACIN), más exactamente en el municipio de Toribio, donde se encuentran los Resguardos Indígenas de Toribío, Tacueyó y San Francisco. Este fue el primer proyecto local, implantado en 1980, y hasta el momento el más exitoso políticamente.

El mayor objetivo del Proyecto fue lograr la autonomía política indígena frente a las amenazas externas que históricamente la han limitado. Sin embargo, a medida que este movimiento se ha desarrollado, y tras 28 años de trabajo, ha constituido tres ejes organizativos: el cultural, el político y el ecológico productivo, bajo los cuales se encuentran los programas de Salud Tradicional, Familia, Etnoeducación, Política Organizativa, Derecho Propio y Producción Ecológica, 
cada uno de ellos con proyectos específicos (Asociación indígena 2007).

Muchos analistas y conocedores de este movimiento lo han caracterizado como un modelo alternativo de sociedad (Zibechi 2008), como una iniciativa de base anti-hegemónica (Ferro 2007), como una alternativa real en medio del conflicto colombiano (González 2008), ya que propone esquemas propios para la construcción política local de la democracia, la producción ecológica, el mantenimiento de la salud tradicional y los valores familiares y comunitarios, pero teniendo en cuenta las exigencias y posibilidades de la coyuntura de cada época (Asociación Indígena 2007: 18-22).

Algunos elementos característicos de la lucha indígena son: la tierra, la unidad, la cultura y la autonomía. La relación del indígena con la tierra es fundamental porque ésta representa la vida y defenderla es preservar la sobrevivencia de la comunidad. La unidad es un elemento característico de la cosmovisión y del mito de origen nasa, por ello esta población trabaja sus acciones colectivas de forma mancomunada y multitudinariamente. Su cultura recoge la esencia de los valores de la comunidad pero dialogando simultáneamente con la coyuntura de cada momento. ${ }^{6}$

Con la Constitución del 1991 y en los años posteriores, el movimiento indígena decide participar en la política oficial del sistema político colombiano, con la perspectiva de capacitar a la gente para votar y que pueden formar parte de los elegidos. Es así como esta región caucana tiene uno de los más altos índices de votación orgánica, la comunidad escoge a sus candidatos y luego los acompaña durante su mandato. Por ejemplo, los cuatro últimos alcaldes de Toribio fueron víctimas de amenazas y algunos de secuestros por parte de los actores armados, en estos episodios la comunidad los respaldó y/ rescató (González 2008: 75-97).

El ejercicio de conciencia y de participación de los nasa se sostiene por medio de la palabra, el derecho de toda la comunidad para ex-

6 "Trabajar la parte cultural desde el sentido de cómo cada pueblo asimila valores, recrea valores y proyecta valores, eso es lo que veo en la parte cultural y en eso pienso que ha jugado un papel importante pues no sé si en los Nasa no más, dicen que los Nasa somos más políticos debido a eso lo que ve bueno de afuera lo coge y lo mete, y lo demás lo recrea y lo proyecta." Aparte de entrevista a Ezequiel Vitonás, líder indígena Silvia Nasa, 21.02.07 (González 2006b: 102-164). 
presarse libremente, para manifestar su pensamiento respecto a las diferentes problemáticas y acciones del colectivo. En los encuentros comunitarios se toman decisiones después de una reflexión colectiva donde la palabra es escuchada y respetada: la de los niños, la de los mayores, la de las mujeres; en los discursos de éstos se observa una conciencia política de lo indígena, de lo comunitario y del contexto político que los rodea.

Asimismo el liderazgo y la gestión de las autoridades son determinadas por la comunidad. Los líderes indígenas "mandan obedeciendo", ellos tienen que presentar informes de su gestión y reconocer sus errores públicamente. Este poder comunitario a nivel interno permite castigar sus incumplimientos, decidir colectivamente sus prioridades y compromisos. Por estas características este proceso político democrático es un modelo ético que retoma el carácter de lo público, de lo colectivo y de la legitimidad de las autoridades. De allí que esta iniciativa sea un ejercicio potencial de democratización para sociedades como la nuestra, cuyos sistemas políticos están definidos por maquinarias electorales, más que por una cultura democrática de participación.

Hacia afuera este poder se manifiesta en la capacidad de interlocución con los actores armados: los líderes, en representación de la comunidad, y algunas veces acompañados por ella, han reclamado sus derechos frente al Estado, a la insurgencia y otros actores armados o ilegales del conflicto. Esta iniciativa se ha distinguido por su posición pacífica, con exigencias estructurales frente a la solución del conflicto; la lucha indígena ha exigido el cese al fuego y la negociación pacífica del mismo. Asimismo el movimiento indígena ha desarrollado una serie de alternativas no formales para superar las consecuencias directas del conflicto en la población, entre éstas se distinguen: sitios de asamblea permanente, la guardia indígena, las marchas, los congresos, las comisiones de la verdad, las comisiones de búsqueda, los territorios de convivencia, los diálogos humanitarios y las zonas especiales (González 2006a).

Otro aporte de la organización política indígena a la producción económica hegemónica, se aprecia en la "Consulta Popular y Ciudadana por la Vida" en contra del Tratado de Libre Comercio (TLC), organizada en 2005 por seis municipios indígenas del norte del Cauca. En ella participaron 58.305 nativos. Esta consulta tenía como finalidad 
dar a conocer la posición de las comunidades indígenas frente al TLC. La iniciativa fue respaldada por otras organizaciones solidarias, organizaciones no gubernamentales a nivel nacional e internacional. Al final los escrutinios confirmaron y legitimaron el descontento indígena, con un $98 \%$ del total de votos.

\section{La Asamblea Constituyente de Mogotes}

La Asamblea Constituyente de Mogotes fue constituida hace poco más de una década en el municipio de Mogotes, departamento del Santander. Actualmente sigue funcionando, pero atraviesa un período de crisis (2005). Se aprecian algunas dificultades para continuar con este proceso pues se requiere de tiempo y recursos humanos actualmente no disponibles, además de que algunos han líderes sido fueron amenazados (CINEP 2007: 32).

La creación de la Asamblea tuvo un detonante puntual: el 11 de diciembre de 1997, el Ejército de Liberación Nacional (ELN) realizó una toma armada del municipio para enjuiciar políticamente al alcalde Dorian Rodríguez y a su padre, Luis Alberto Rodríguez (ex alcalde), a quienes juzgaban responsables de la pobreza, la corrupción política y administrativa del municipio. En la toma fue secuestrado el alcalde y murieron cinco personas. Aquella noche, la población, animada por la Iglesia Católica de la Diócesis de Socorro y San Gil y representantes de las organizaciones sociales, eclesiales y populares, se organizó para impedir la toma, obligando a los milicianos a replegarse y liberar al alcalde; el pueblo evaluó que efectivamente el alcalde había tenido un mal manejo del dinero público y le obligo a su renuncia mediante un plebiscito electoral. El plebiscito arrojó un número cercano a 5.000 votos de confirmación entre un total cercano a los 7.000.

Luego del plebiscito se hizo reconocimiento a la Asamblea, que estaba constituida por unos 260 delegados de todos los sectores sociales y geográficos del municipio, quienes realizaron una junta directiva, a partir de la cual se desarrolló un proceso participativo para "derrotar la corrupción causante de la violencia que ha azotado al municipio con la peor de las armas, la pobreza", alrededor de esta meta también se 
propusieron otros objetivos. ${ }^{7}$ En el ejercicio de la soberanía popular en cabeza del pueblo de Mogotes la Asamblea emitió mandatos en torno a diferentes temas como la educación, el desarrollo, Derechos Humanos y paz, soberanía, y el presupuesto (presupuesto municipal participativo), constituyendo su voz en un mandato político sin precedentes en la historia de Colombia. Todo esto fue implementado entre $1997 \mathrm{y}$ 2003, período que se considera una época de auge y consolidación de este proceso.

Para ese año los municipios de Colombia habían vivido más de 100 tomas guerrilleras sin respuestas de la sociedad civil y la Asamblea fue un camino nuevo para todos. Hacia finales de los noventa y comienzos de 2000 la Constituyente del Tolima, la Constituyente del Municipio de Tarso, la Constituyente de Nariño han visto en la experiencia de Mogotes una nueva y verdadera esperanza para salir de la violencia, la corrupción y la pobreza. Así, estos modelos urbanos de participación ciudadana fueron proliferando progresivamente en diferentes lugares del país, en gran parte impulsadas por los gobiernos locales y departamentales.

Entre las fortalezas del proceso de Mogotes están el rechazo y resistencia a los actores armados, expreso en las acciones colectivas realizadas por la población de Mogotes para impedir la toma guerrillera y reivindicar su autonomía colectiva como sociedad civil. Una de las lecciones más importantes para Mogotes fue pasar de una ciudadanía representada a ser una ciudadanía políticamente representada por sí misma. Se desarrolló una nueva cultura de participación, un empoderamiento local y la oxigenación de la política.

Otra fortaleza es el ejercicio de veeduría ciudadana frente al ejercicio gubernamental de la alcaldía, frente al cual se desarrolló una interlocución estatal y de representación de todos los sectores. A nivel nacional esta experiencia abrió un camino para desarrollar procesos constituyentes en otros municipios del país. Los actores armados se fueron alejando poco a poco de la región, permitiendo la reconstrucción del tejido social afectado por las reacciones violentas.

7 Los objetivos de la Asamblea fueron: generar un proceso de desarrollo comunitario que permitiera superar una de las causas de la violencia que es la pobreza; ejercer el derecho de la soberanía popular a través de la Asamblea Constituyente; establecer la vigencia de los Derechos Humanos en la región; trabajar por la paz, la justicia y los derechos vulnerados; alejar los actores armados de la región. 
Este proyecto es muy interesante porque es aplicable a las sociedades urbanas. Una de las preguntas que me han surgido en este proceso de investigación es cómo este Movimiento Nasa cimienta gran parte de sus fortalezas en su cultura indígena y rural. Mientras que el ejemplo de este municipio le dota de otras características que tal vez pueden ser más aplicables a la mayoría del pueblo colombiano.

En cuanto al reconocimiento externo que han tenido los procesos, la Asamblea de Mogotes obtuvo el "Premio Nacional de Paz" en el año 1999 y el Movimiento Nasa recibió este mismo galardón en los años 2000 y 2004, asimismo este último recibió el "Premio Nacional de Planeación al mejor Municipio" (1998) y el "Premio Ecuatorial de Naciones Unidas" (2004) entre 360 candidaturas del mundo como una iniciativa de desarrollo social y político. El año pasado el Proyecto Nasa fue nominado al Nobel de Paz (Actualidad étnica 2007a; 2007b).

\section{Tensiones}

A continuación se expondrán algunas tensiones observadas en ambos procesos y en general en varios de los procesos locales de características similares. Una tensión inicial a destacar consiste en la discrepancia entre el mejoramiento real de la calidad de vida de los habitantes y las aspiraciones reinvindicadas. Todo proceso social tiende a observar unas aspiraciones discursivas muy altas que no siempre son materializables para el común de los habitantes, en muchos casos las grandes transformaciones se observan en los círculos directamente vinculados a las acciones colectivas de los movimientos.

Otra tensión significativa es el ejercicio simultáneo del funcionariado público (Estado local) y el liderazgo comunitario (intereses colectivos). Por ejemplo, un líder comunitario antes de ser elegido alcalde, representa y defiende solamente los intereses de los movilizados, sin embargo cuando es escogido representante oficial debe representar los intereses del Estado y al mismo tiempo los comunitarios, pero éstos no siempre coinciden.

Otro punto conflictivo es el aumento progresivo de los recursos económicos y la burocratización, un aumento de recursos no siempre favorece la movilización o la claridad de sus iniciativas, sino que, en algunos casos, ha degenerado en vicios tradicionales de la clase dirigente y en burocratización. Esto hace que gran parte de las discusiones 
siones internas de estas iniciativas pasen de ser políticas a desradicalizarse y ser meramente pragmáticas: ¿cómo repartimos el dinero?, ¿cuáles van a ser las asignaciones, etc.? relegando con ello las prioridades políticas o sociales que inicialmente motivaron su surgimiento. Asimismo, otro punto álgido es el apoyo o la dependencia de la cooperación externa: ¿cómo se acepta la financiación externa para que finalmente asegure una autonomía interna de los procesos?

Por último, una tensión inevitable es el dilema de crear consenso en medio del pluralismo y pluralismo en el consenso. Nuestras sociedades en América Latina son profundamente plurales, y en esta heterogeneidad se vuelve imperativo articular unos mínimos políticos, éticos o unas alianzas de confianza que faciliten consensos de diferente tipo, especialmente aquellos más permanentes y no solamente producto de las oportunidades políticas facilitadas por la coyuntura.

\section{Conclusiones}

Para cerrar esta reflexión se presentan en lo siguiente algunas conclusiones puntuales:

- Una razón por la cual el sistema político colombiano no ha materializado una participación ciudadana y una cultura política verdaderamente democrática, participativa e incluyente, -a pesar de haber establecido ciertos mecanismos constitucionales para este fin en 1991-, es la presencia de varios nudos estructurales que históricamente han limitado a los ciudadanos colombianos. En este texto se abordaron brevemente tres: 1) la presencia de una cultura dominante excluyente y unas prácticas clientelistas de inclusión; 2) la violencia sistemática con la cual los colombianos hemos aprendido a "sobrevivir por medio de acciones violentas"; y 3) la ilegalidad, como posibilidad productiva ampliamente rentable, ha formado ciudadanos ausentes de voluntad y conciencia política.

- En medio del panorama de recrudecimiento del conflicto armado, a lo largo y ancho del territorio nacional se están gestando distintas iniciativas de paz, sobre las cuales la autora categoriza la siguiente tipología: iniciativas de base anti-hegemónicas, iniciativas de base en resistencia a la violencia y el conflicto, iniciativas de coordinación regional y nacional, iniciativas de desarrollo y paz, iniciativas de educación para la paz y resolución de conflictos, ini- 
ciativas estatales de diálogo y negociación, iniciativas recientes de movilización masiva e iniciativas de base a favor de la democracia y el desarrollo local. Todas estas iniciativas comprueban el esfuerzo de muchas comunidades que -afectados por el conflicto armado y social-, han hecho grandes esfuerzos por transformar la realidad colombiana.

- El Proyecto Nasa como una iniciativa rural local ha sido caracterizado como una propuesta indígena de gran envergadura política para la realidad de la confrontación armada y social del país. Gracias a sus continuos esfuerzos, en los últimos años este proyecto ha vivido un auge de reconocimiento externo siendo identificado como una alternativa en medio de la confrontación armada, un modelo alternativo de sociedad y una iniciativa de base antihegemónica. Este proyecto ha mostrado resultados con esquemas propios para la superación de las consecuencias del conflicto, la construcción política local de la democracia, la gestación de conciencia política comunitaria y con ella de cultura política. De la misma manera que frente al conflicto, esta iniciativa ha mostrado muchos caminos alternativos para el mantenimiento del tejido social y la consecución de una cierta autonomía frente a los actores armados ilegales.

- La Asamblea Constituyente de Mogotes estableció un nuevo camino de participación política, la construcción de lo público y la superación de la violencia, la corrupción y la pobreza en sus expresiones locales. Este modelo urbano de participación ciudadana fue el ejemplo a imitar en diferentes lugares del país, aunque vale la pena aclarar que estos procesos constituyentes fueron impulsados en gran parte por los gobiernos locales y departamentales. Esta iniciativa local verifica la posibilidad de crear una representación política desde la ciudadanía, un empoderamiento local, una nueva cultura de participación con veeduría ciudadana y, por tanto, la oxigenación de la política tradicional. Respecto al conflicto, esta iniciativa mostró una vía para la reconstrucción del tejido social y la interlocución con la insurgencia.

- En este análisis es pertinente valorar las fortalezas de estas iniciativas locales respecto a la construcción de una cultura democrática participativa, democrática e incluyente, pero también es indispensable hacer un reconocimiento de las posibles tensiones internas 
que también deben afrontar estos procesos, entre ellas el texto se acerca a la coherencia entre el discurso y el mejoramiento de la calidad de vida de los miembros de estos procesos; asimismo revisa la dualidad presentada entre el funcionariado público y liderazgo comunitario. Otras tensiones son las causadas por el ingreso de dinero y el manejo de la burocratización, la dependencia externa o la desradicalización política; por último, se establece la existencia de una zona gris entre la edificación de consenso en medio del pluralismo y de pluralismo en medio del consenso.

\section{Bibliografía}

Actualidad étnica, Periódico virtual (2007a): "Colombia / Indígenas nominados a nobel de paz”. Bogotá, 09.02.2007. En: <www.etniasdecolombia.org/ actualidadetnica/detalle.asp?cid $=4824>(16.02 .2007)$.

- (2007b): "Colombia / Resistencia y alternativa desde el Norte del Cauca". Bogotá, 09.03.2007. En: <www.nasaacin.net/audios/entrev_p_antonio.mp3> (18.04. 2007).

AFP (2007): "Delitos electorales denuncia misión electoral de la OEA". En: $<$ www.colombia.indymedia.org/news/2007/11/74405.php> (10.01.2009).

Arango, Carlos/Misas, Martha/López, Enrique (2004): Economía Subterránea en Colombia 1976-2003: una medición a partir de la demanda de efectivo. Bogotá: Banco de la República (<www.banrep.gov.co/docum/ftp/borra335.pdf>; 10.01 . 2009).

Asociación Indígena de Cabildos de Toribio, San Francisco, Tacueyo del Proyecto Nasa (2007): Proyecto Nasa: un sueño para continuar con las raíces en la tierra. Cali: Pontificia Universidad Javeriana/Proyecto Nasa. Diciembre 2007.

Barié, Cletus Gregor (2000): "Nicht nur papel mojado. Minderheitenrechte in Lateinamerika". En: Lateinamerika. Analysen-Daten-Dokumentation, 16, 42, pp. 7584.

Camacho Guizado, Álvaro (1991): "Cinco tesis sobre narcotráfico y violencia en Colombia”. En: Revista Foro, 15, pp. 65-73.

Cátedra Nasa Unesco/ACIN (Asociación de Cabildos Indígenas del norte del Cauca) (2000): Lo que cuentan los mayores del Resguardo de Tacueyó. Toribío: Cauca.

CINEP (Centro para la Investigación y Educación Popular) (2007): Sistematización y análisis de las Asambleas Constituyentes en Colombia. Bogotá.

Elias, Norbert (1996): "Transformaciones de la agresividad". En: El proceso de la civilización: investigaciones psicogenéticas y sociogenéticas. México, D.F.: FCE, pp. 229-242.

Ferro, Juan Guillermo (2007): Caminando la palabra: el proceso emancipatorio del movimiento Nasa del Norte del Cauca, Colombia. Tesis doctoral. México, D.F.: 
Universidad Nacional Autónoma de México, Facultad de Estudios Latinoamericanos.

García-Durán, Mauricio (coord.) (2004): Alternativas a la Guerra: Iniciativas y Procesos de paz en Colombia (Núm. Extraordinario de la Revista Controversia). Bogotá/London: CINEP.

González Piñeros, Nidia Catherine (2006a): "Indígenas: Modelo alternativo de vida y de derecho. ¿Qué papel juegan los indígenas en la búsqueda de la paz?”. En: Colombia: caminos para salir de la violencia. Madrid/Frankfurt: Iberoamericana/Vervuert, pp. 329-351.

- (2006b): Resistencia Indigena: alternativa en medio del conflicto colombiano. Cali: Pontifica Universidad Javeriana.

- (2006c): Colombia hacia una democracia participativa, contribución indígena, 1990-2003. Cali: ídem supre.

- (2008): "Frieden und Demokratiebildung: das Beispiel des indigenen Nasa-Volks in Kolumbien". En: Blaser, Jutta/Lustig, Wolf (Hrsg.): Das Politische Erwachen der Indigenen Völker in Lateinamerika. Vol. 4. Mainz: Johannes GutenbergUniversität, pp. 75-97.

Hernández, Esperanza (2005): Resistencia civil artesana de paz: experiencias indígenas, afrodescendientes y campesinas. Bogotá: Pontificia Universidad Javeriana.

Hernández, Jorge (2002): "La resistencia civil en caliente: una contribución a la pacificación del conflicto en Colombia”. En: Revista Sociedad y Economía (Cali), 2, pp. 25-48.

- (2003): "Formas de acción colectiva contra la guerra en el movimiento indígenas del suroccidente colombiano". Ponencia presentada en el Seminario Internacional sobre Resistencia Civil y Acción Política No Violenta. Bogotá: Alcaldía Mayor de Bogotá/Universidad Nacional de Colombia, pp. 11-14.

INDEPAZ (Instituto de estudios para el dedarrollo y La Paz) (2000): Agenda ciudadana para la paz. Propuestas Humanitarias y Poder Ciudadano: Cátedra para la paz, la vida y la libertad. Bogotá: Quebecor Impreandes, Módulo 3.

LEGIS (2007): Constitución politica de Colombia: anotada. Colombia: Legis Editores.

Molina Ramírez, José Rafael (2007): “Aumentan amenazas contra candidatos”. En: El Universal. Banco de la República (<www.kas.de/upload/auslandshomepages/ kolumbien/el-universal_010807.pdf $>$; 10.01.2009).

PNUD (Programas de la Naciones Unidas para el Desarrollo Humano) (2003): El Conflicto, callejón con salida: Informe Nacional de Desarrollo Humano para Colombia. Bogotá: Editorial El Malpensante.

Rettberg Beil, Beatriz Angelika (2006): Buscar la paz en medio del conflicto: un propósito que no da tregua: un estudio de las iniciativas de paz en Colombia. Bogotá: Universidad de los Andes/CESO/PNUD.

UAEDT (Unidad Administrativa especial de Desarrollo Territorial)/(DNP) Departamento Nacional de Planeación (1998): Avances y dificultades en la ejecución de los recursos asignados a los resguardos indigenas provenientes de los ingresos corrientes de la Nación (Bogotá) (Documentos para el desarrollo territorial, 12). 
- (2001): Seguimiento y evaluación de la participación de los resguardos indígenas en los ingresos corrientes de la Nación para el periodo 1998 y 1999 (Bogotá) (Documentos para el desarrollo territorial, 54).

Wills Obregón, María Emma (2002): "Inclusión partidista y exclusión cultural en Colombia: pistas para comprender su relación”. En: Análisis político, 46, pp. 4457.

Zibechi, Raúl (2008): "Cuando el sótano dijo basta". En: Noticias ACIN. ( $<$ www.nasaacin.org/noticias.htm? $\mathrm{x}=7775>$; 10.01.2009). 
